\title{
Enantioselective [3+2] Cycloaddition of Allenylsilanes with $\alpha$-Imino Esters
}

Metal-Catalyzed

Asymmetric

Synthesis and

Stereoselective

Reactions

Key Words

[3+2]

cycloaddition

alkylallenylsilanes

iminoesters

enantioselective

reactions

dihydroprolines

copper(I)
Significance: The first enantioselective [3+2] cycloaddition reaction of 1-alkyl-substituted allenylsilanes with an $\alpha$-imino ester is reported using a chiral $\mathrm{Cu}(\mathrm{l})$ catalyst. The presence of an $\alpha$-alkyl group was essential for the reaction to succeed and a range of alkyl substituents was demonstrated. Use of a highly reactive aldimine is necessary to drive the reaction and only one example of an iminoester substrate gave the desired product. The vinyl silane functionality in the dehydroproline products allows further derivatization.

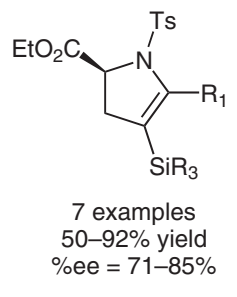

SYNFACTS Contributors: Mark Lautens, Josephine Yuen

Comment: Electron deficient olefins, aldehydes and N,O-hemiacetals have previously been demonstrated to undergo [3+2] cycloaddition reactions with 1-methylallenylsilane, producing fivemembered carbocycles and heterocycles, respectively. However, their application to enantioselective reactions has been limited. The scope has now been extended to include a chiral Lewis acid-catalyzed addition of allenylsilane to an activated imine, creating enantioenriched heterocyclic compounds which are abundant in natural products and biologically active compounds. The scope of imines is very limited at this time. Changing the solvent to THF led to dramatically lower yields. 